\title{
Manufacturing of Long-Length Rods of Ultrafine-Grained Ti-Ni Shape Memory Alloys
}

\author{
Sergey Prokoshkin ${ }^{1, a}$, Irina Khmelevskaya ${ }^{1, b}$, Vladimir Andreev ${ }^{2, c}$, \\ Roman Karelin ${ }^{1, \mathrm{~d}}$, Victor Komarov ${ }^{1,3, \mathrm{e}^{*}}$ and Alibek Kazakbiev ${ }^{1, \mathrm{f}}$ \\ ${ }^{1}$ NUST "MISIS", Moscow, Russia \\ ${ }^{2}$ Industrial Center MATEK-SMA, Russia \\ ${ }^{3}$ TU Bergakademie Freiberg, Germany \\ aprokoshkin@tmo.misis.ru, ${ }^{b}$ khmel@tmo.misis.ru, candreev.icmateks@gmail.com, \\ drdkarelin@gmail.com, ${ }^{\mathrm{e}}$ vickomarov@gmail.com, ${ }^{\mathrm{f}}$ kazakbiev@yandex.ru
}

\begin{abstract}
Keywords: shape memory alloys, titanium nikelide, thermomechanical treatment, rotary forging, functional properties.
\end{abstract}

\begin{abstract}
Ti-Ni shape memory alloys were subjected to a rotary forging (RF) from the diameter of 20 or $12 \mathrm{~mm}$ to $5 \mathrm{~mm}$ at relatively low temperatures of 450 and $350{ }^{\circ} \mathrm{C}$. The structure was studied using X-ray diffraction analysis and transmission electron microscopy. Mechanical properties were determined by uniaxial tensile and Vickers hardness tests, and the maximum completely recoverable strain by a thermomechanical method. The obtained results showed that RF at low temperatures allows manufacturing $3 \mathrm{~m}$-long Ti-Ni rods. A mixed submicrocrystalline and nanosubgrained structure with an average size of structural elements of $118 \pm 7 \mathrm{~nm}$ after forging from $20 \mathrm{~mm}$, and $126 \pm 7 \mathrm{~nm}$ after forging from $12 \mathrm{~mm}$ at $350{ }^{\circ} \mathrm{C}$ provides the highest mechanical $\left(\sigma_{\mathrm{B}}=1113 \mathrm{MPa}\right.$ after forging from $20 \mathrm{~mm}$, and $1065 \mathrm{MPa}$ after forging from $12 \mathrm{~mm}$ ) and functional (maximum completely recoverable strain of $8.0 \%$, after post-deformation annealing at $400{ }^{\circ} \mathrm{C}, 1 \mathrm{~h}$ ) properties as compared to the initial state before $\mathrm{RF}$ (700 MPa, and $4.4 \%$, respectively).
\end{abstract}

\section{Introduction}

Ti-Ni-based shape memory alloys (SMA) are widely used in different fields of engineering and medicine as a functional material for production of various shape-memory devices, such as clips and stents for application in cardiovascular surgery, functional elements of space aerials, thermosensitive elements of fire alarm systems etc. [1-3]. Configuration of the devices, incorporating shape-memory elements, permanently complicates due to the enhanced sophistication of their construction, decrease in metal consumption, increase in necessary recovery stress value and additional requirements to operating temperature range [1, 4]. This complexity leads to the permanent increase in the combination of SMA functional properties. For manufacturing of the most previously mentioned devices, semi-finished long-length Ti-Ni rods (the most frequently used shape memory alloy) with a diameter of $5 \mathrm{~mm}$ or less are used. It is well-known, that the application of thermomechanical treatment (TMT) including severe plastic deformation (SPD) at relatively low temperatures $\left(300-500^{\circ} \mathrm{C}\right.$ ) for this group of alloys, allows obtaining ultrafine-grained (submicroand nano-crystalline) structure and considerably improve mechanical and functional properties. However, today the possibility of ultrafine-grained structure formation in bulk and long-length billets, is limited by the existing schemes of severe plastic deformation (equal channel angular pressing, MaxStrain deformation, abc-pressing), which make it possible to obtain such structure type only in small experimental samples. In situation, for industrial production, it is necessary to search for a way of ultrafine-grained structure formation in bulk and long-length billets. [5-8].

One of the most frequently used processes for obtaining round and long-length rods is a hot rotary forging (RF). Traditionally, forging is carried out at sufficiently high temperatures (800$900{ }^{\circ} \mathrm{C}$ ), since this greatly simplifies the deformation process. At such a high temperature, it is impossible to obtain an ultrafine-grained structure in Ti-Ni alloys. It follows from the previous 
experience of the use of other deformation modes that the deformation temperature should be $450{ }^{\circ} \mathrm{C}$ or less for this structure formation [5-8].

The results of the rotary forging application to Ti-Ni shape memory alloy at low temperatures $\left(450{ }^{\circ} \mathrm{C}\right.$ and $350{ }^{\circ} \mathrm{C}$ ) is described and discussed in the present paper for the first time.

\section{Experimental}

In the present work Ti-50.0 at.\% Ni alloy was studied. The billets for rotary forging, rods $20 \mathrm{~mm}$ in diameter, were produced by screw rolling at $850-950{ }^{\circ} \mathrm{C}$ with reduction of $7-20 \%$ per pass and interpass heating (hot-rolled state). The post-deformation annealing at $750{ }^{\circ} \mathrm{C}, 30 \mathrm{~min}$ after screw rolling - served as a reference treatment (RT).

The billet in the process of rotary forging is deformed from all sides, its cross-section area decreases, and length increases. At the same time, rotational movements can perform both working tool-strikers and rod. A schematic representation of rotary forging procedure is shown in Fig. 1.

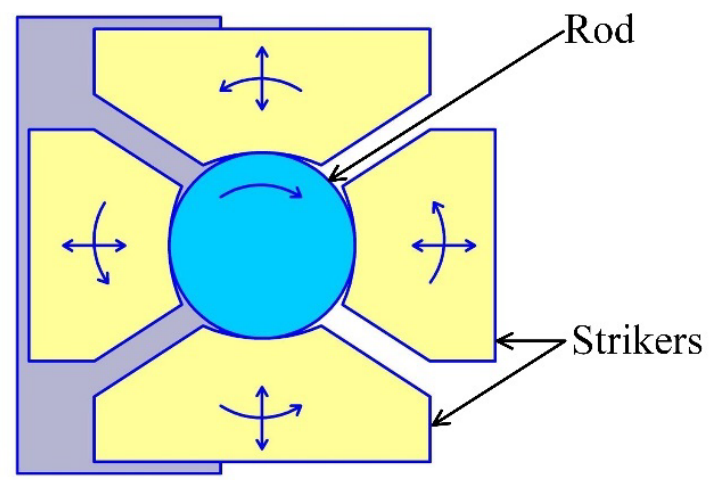

Fig. 1. Schematic representation of rod deformation during rotary forging.

The first group of the hot-rolled rods was rotary forged from a diameter of 20 to $5 \mathrm{~mm}$ at 450 and $350{ }^{\circ} \mathrm{C}$ with particular strains from 1 to $5 \%$. The second group of hot-rolled rods was rotary forged from a diameter of 20 to $12 \mathrm{~mm}$ at $850{ }^{\circ} \mathrm{C}$ with particular strains from 5 to $10 \%$ and after post-deformation annealing at $750{ }^{\circ} \mathrm{C}, 30 \mathrm{~min}$, from 12 to $5 \mathrm{~mm}$ at 450 and $350{ }^{\circ} \mathrm{C}$, with deformation degree from 1 to $5 \%$. All deformation regimes are designated like in the following example: $\mathrm{RF}_{450} \varnothing 12-5$, where $\mathrm{RF}$ is rotary forging, 450 - forging temperature in ${ }^{\circ} \mathrm{C}, 12$ and $5-$ initial and ultimate diameters in $\mathrm{mm}$, respectively. A post-deformation annealing at the deformation temperature and at a temperature exceeding the deformation temperature by $50{ }^{\circ} \mathrm{C}$ was performed after all regimes of thermomechanical treatment.

The determination of the deforming forces and the corresponding stresses directly during rotary forging is impossible due to technological features of the equipment. To evaluate the deforming stresses, the experimental modeling was performed on a deformation simulator WUMSI. The compression tests were carried out at 350 and $450{ }^{\circ} \mathrm{C}$ with a strain rate $\dot{e}=5 s^{-1}$ which correlates with the deformation parameters of rotary forging.

The structure was studied at room temperature using "Ultima IV Rigaku” X-ray diffractometer and "JEM-2100" transmission electron microscope. Temperature ranges of martensitic transformations were studied using the "Mettler Toledo" calorimeter and by a thermomechanical method. Starting and finishing temperatures of forward martensitic transformation $\mathrm{M}_{\mathrm{s}}$ and $\mathrm{M}_{\mathrm{f}}$, starting and finishing temperatures of $B 2$ to $R$ transformation $R_{s}$ and $R_{f}$, starting and finishing temperatures of reverse martensitic transformation $A_{s}$ and $A_{f}$ were determined. The Vickers hardness measurements were carried out at room temperature using a "LECOM 400-A" tester under a load of $1 \mathrm{~N}$. The mechanical properties were determined at room temperature by the uniaxial tensile tests using universal tensile machine "INSTRON 3382" with a deformation rate of $4 \mathrm{~mm} / \mathrm{min}$. The maximum completely recoverable strain was estimated by a thermomechanical method using band samples. 


\section{Results and Discussion}

Deformation behavior. The results of the physical modeling (flow curves for Ti-50.0 at.\% Ni alloy) are shown in Fig. 2. It can be seen in Fig. 2 that the deformation at $350{ }^{\circ} \mathrm{C}$ goes into the steady state at $e=0.4$, and at $450{ }^{\circ} \mathrm{C}$ it occurs later at $e=0.6$. This indicate that the hardening process is more pronounced at a low temperature, which contributes to a more intensive hardening of the material and to the refinement of the structure. Both values of steady state stresses at 350 and $450{ }^{\circ} \mathrm{C}(750 \mathrm{MPa}$ and $1000 \mathrm{MPa}$, respectively) do not lead to the formation of cracks.

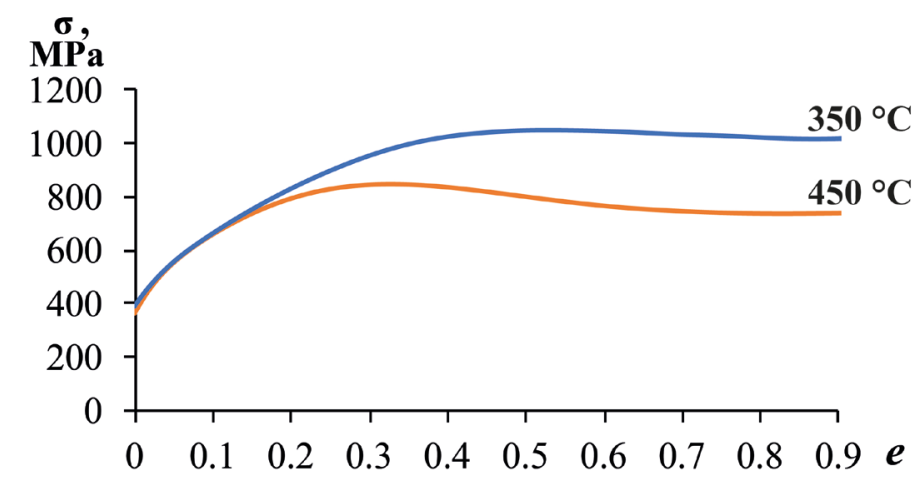

Fig. 2. Flow curves of Ti- 50.0 at.\% Ni alloy.

X-Ray diffraction analysis. The phase composition of the alloy as a result of rotary forging under different regimes is estimated using X-ray diffractograms shown in Fig. 3.

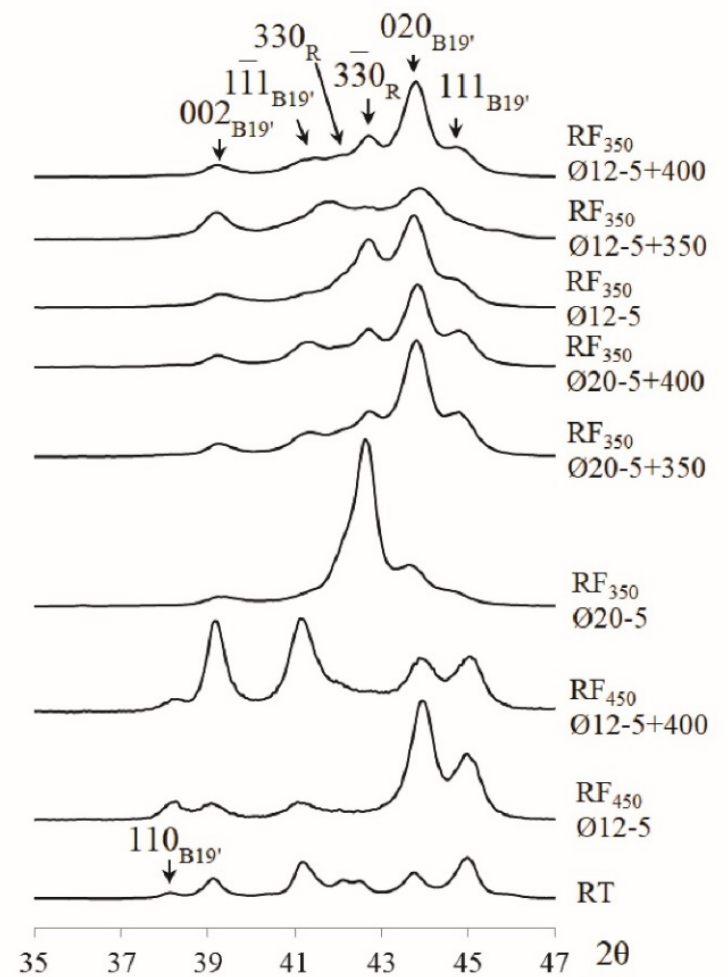

Fig. 3. X-ray diffraction patterns of the rotary forging under different regimes.

At room temperature, after RT, the main phase is B19'-martensite. The rhombohedral R-phase and B2 austenite are also present (not more than $20 \%$ ). After $\mathrm{RF}_{450} \varnothing 12-5$, a close phase composition is defined. The lowering of the forging temperature to $350{ }^{\circ} \mathrm{C}$ leads to an increase in deformation hardening, which is evident from the broadening of the $002_{\mathrm{B} 19}$ peak, and to a decrease in the amount of martensite due to the formation of the R-phase and B2-austenite. After $\mathrm{RF}_{350} \varnothing 20$ 5 , the crystal lattice defectness and the amount of R-phase are slightly higher than after $\mathrm{RF}_{350} \varnothing 12$ 5. The post-deformation annealing leads to the decrease in lattice defectness and increase in amount of B19'-martensite for both deformation regimes. 
Transmission electron microscopy. The TEM study after all deformation regimes reveals that a very complex ultrafine grained structure forms (Fig. 4). The analysis of bright field, dark field images and electron diffraction patterns shows that there are three main phases, i.e., B19'martensite, R-martensite, and B2-austenite. A well-developed dislocation substructure with high density of free dislocations of about $10^{11} \mathrm{~cm}^{-2}$ and incompletely equiaxed grains and subgrains of submicron size are formed. In the dark field images taken in the strong reflections of the first diffraction ring, closely oriented adjacent to each other structural elements (subgrains) and individual bright elements (grains with high-angle misorientations) are observed (Fig. 4). Both discrete and continuous arc reflections can be observed in the electron diffraction patterns obtained after different deformation regimes. The value of the azimuthal broadening of reflections shows that the misorientation of the crystal lattice in these regions reaches several degrees. Numerous individual point reflections are also present. These electron diffraction patterns are characteristic of the regions with a mixed polygonized (nanosubgrained) and nanograined structure [9-11].

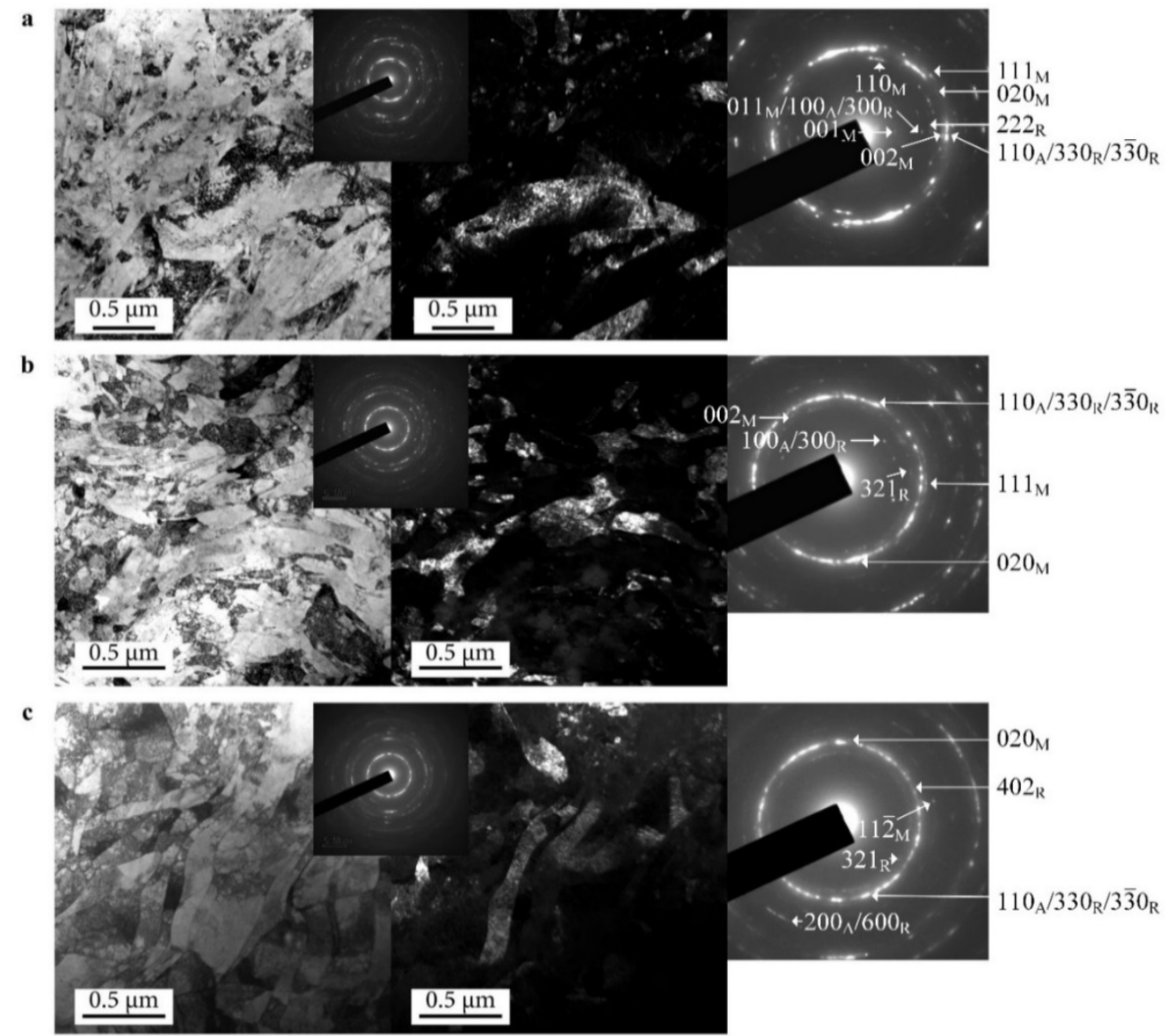

Fig. 4. Microstructure of samples after various deformation regimes: $\mathrm{RF}_{450} \varnothing 12-5$ (a), $\mathrm{RF}_{350} \varnothing 12-5$ (b), $\mathrm{RF}_{350} \varnothing 20-5$ (c). Transmission electron microscopy: bright and dark fields images, and electron diffraction patterns. Spots of various phases are indexed as follows: B2 as A, B19' as $\mathrm{M}, \mathrm{R}$ as $\mathrm{R}$.

The statistical analysis of the structure elements size was carried out using bright field images in which the boundaries of grains and subgrains are clearly visualized in contrast to the dark field images, where not all subgrain boundaries can be distinguished. The size of the structural elements was determined without a differentiation between grain boundaries and subboundaries. According to the results of the analysis, after $\mathrm{RF}_{450} \varnothing 12-5$, a mixed submicrocrystalline structure (average grains/subgrains size of $138 \pm 7 \mathrm{~nm}$ ) with small regions of nanosubgrained structure and high density of free dislocations is formed. The post-deformation annealing decreases the amount of lattice defects and increases the uniformity of structural elements. It can be observed by the decrease in the azimuthal broadening of the reflexctions in the diffraction pattern. Average size of structural elements after annealing does not change significantly $(136 \pm 7 \mathrm{~nm})$. 
The decrease of the deformation temperature to $350{ }^{\circ} \mathrm{C}$ allowed obtaining a mixed submicrocrystalline and nanosubgrained structure with numerous nanograins. After $\mathrm{RF}_{350} \varnothing 12-5$, the average size of structural elements was $126 \pm 7 \mathrm{~nm}$, and after $\mathrm{RF}_{350} \varnothing 20-5-118 \pm 7 \mathrm{~nm}$. These results show that forging from a larger diameter does not lead to a noticeable additional grain refinement.

Temperature ranges of martensitic transformations and shape recovery. The results of the differential scanning calorimetry showed that decrease of the rotary forging temperature from 450 to $350{ }^{\circ} \mathrm{C}$ leads to significant lowering of martensitic transformation temperatures, as well as to an increase in the width of the direct martensitic transformation range. That correlates, well, with the decrease in the martensite amount observed in the X-ray diffractograms (Fig. 3) and electron diffraction patterns (Fig. 4 a, b). In addition, the reverse martensitic transformation range is broadened along the temperature axis (Table 1).

Table 1. Results of differential scanning calorimetry.

\begin{tabular}{|c|c|c|c|c|c|c|c|c|}
\hline Treatment & $\mathrm{R}_{\mathrm{s},}{ }^{\circ} \mathrm{C}$ & $\mathrm{R}_{\mathrm{f},}{ }^{\circ} \mathrm{C}$ & $\mathrm{M}_{\mathrm{s},}{ }^{\circ} \mathrm{C}$ & $\mathrm{M}_{\mathrm{f},}{ }^{\circ} \mathrm{C}$ & $\mathrm{A}_{\mathrm{s},}{ }^{\circ} \mathrm{C}$ & $\mathrm{A}_{\mathrm{f},}{ }^{\circ} \mathrm{C}$ & $\mathrm{A}_{\mathrm{s}}-\mathrm{A}_{\mathrm{f},}{ }^{\circ} \mathrm{C}$ & $\mathrm{R}_{\mathrm{s}}-\mathrm{M}_{\mathrm{f},}{ }^{\circ} \mathrm{C}$ \\
\hline Reference & - & - & 38 & 5 & 42 & 64 & 22 & - \\
\hline $\mathrm{RF}_{450} \varnothing 12-5$ & 70 & - & 30 & -14 & 55 & 91 & 36 & 84 \\
\hline $\mathrm{RF}_{350} \varnothing 12-5$ & 63 & 4 & 29 & -42 & 10 & 71 & 61 & 105 \\
\hline
\end{tabular}

Determination of the shape recovery temperature range after induced strain $\varepsilon_{i}=2 \%$ using the thermomechanical method showed that rotary forging at lower temperatures leads to a slight decrease of $A_{s}$ and $A_{f}$ temperatures ( $A_{s}$ : from 42 to $30-40{ }^{\circ} \mathrm{C}$; $A_{\mathrm{f}}$ : from 64 to $50-60{ }^{\circ} \mathrm{C}$ ), however, they remain in the operating temperature range and can be regulated by post-deformation annealing practically to the level of the reference treatment.

Mechanical and functional properties. The measurements of the Vickers hardness show high hardness value after the $\mathrm{RF}_{350}$. The hardness values after forging both from the diameter of $12 \mathrm{~mm}$ and $20 \mathrm{~mm}$ differ slightly, which indicates that an increase in the accumulated strain during rotary forging does not lead to an additional hardening (Table 2).

Table 2. Mechanical and functional properties after all regimes of rotary forging.

\begin{tabular}{|c|c|c|c|c|c|c|c|}
\hline Treatment & $\begin{array}{c}\sigma_{\mathrm{cr}} \\
\mathrm{MPa}\end{array}$ & $\begin{array}{c}\sigma_{0,2} \\
\mathrm{MPa}\end{array}$ & $\begin{array}{c}\Delta \sigma, \\
\mathrm{MPa}\end{array}$ & $\begin{array}{c}\sigma_{\mathrm{B}}, \\
\mathrm{MPa}\end{array}$ & $\begin{array}{c}\delta, \\
\%\end{array}$ & $\begin{array}{c}\mathrm{HV}, \\
\mathrm{MPa}\end{array}$ & $\begin{array}{c}\varepsilon_{r, 1}^{\max } \\
\%\end{array}$ \\
\hline Reference & 100 & 430 & 330 & 700 & 28 & 191 & 4.4 \\
\hline $\mathrm{RF}_{450} \varnothing 12-5$ & 127 & 760 & 633 & 917 & 48 & 280 & 5.3 \\
\hline $\mathrm{RF}_{450} \varnothing 20-5$ & 225 & 930 & 705 & 1172 & 17 & 290 & 6.0 \\
\hline $\mathrm{RF}_{450} \varnothing 20-5+500^{\circ} \mathrm{C}$ & 110 & 860 & 750 & 1111 & 24 & 270 & 6.8 \\
\hline $\mathrm{RF}_{350} \varnothing 12-5$ & 210 & 905 & 695 & 1060 & 31 & 304 & 6.8 \\
\hline $\mathrm{RF}_{350} \varnothing 12-5+400^{\circ} \mathrm{C}$ & 200 & 740 & 540 & 1045 & 46 & 295 & 8.0 \\
\hline $\mathrm{RF}_{350} \varnothing 20-5$ & 200 & 765 & 565 & 1113 & 32 & 322 & 5.5 \\
\hline $\mathrm{RF}_{350} \varnothing 20-5+400^{\circ} \mathrm{C}$ & 170 & 640 & 470 & 1006 & 37 & 284 & 8.0 \\
\hline
\end{tabular}

The mechanical behavior during tensile tests at room temperature after $\mathrm{RF}_{350}$ is characterized by strong deformation hardening and lack of a yielding plateau in stress-strain diagrams, which appears only after annealing. After all RF regimes the strength characteristics $\left(\sigma_{0,2}=640-930 \mathrm{MPa}, \sigma_{\mathrm{B}}=\right.$ 917-1172 $\mathrm{MPa})$ are much higher than after RT $\left(\sigma_{0,2}=430 \mathrm{MPa}, \sigma_{\mathrm{B}}=700 \mathrm{MPa}\right)$. The maximum ultimate tensile strength is observed after $\mathrm{RF}_{350} \varnothing 20-5\left(\sigma_{\mathrm{B}}=1113 \mathrm{MPa}\right)$. The difference in strength after forging from $\varnothing 20$ and $\varnothing 12 \mathrm{~mm}$ was only $53 \mathrm{MPa}$. High elongation to failure after all regimes of rotary forging should also be noted $(\delta=31-48 \%$ ). Maximum completely recoverable strain of $8.0 \%$ was obtained after $\mathrm{RF}_{350}$ both for forging from 20 and $12 \mathrm{~mm}$ plus post-deformation annealing $400{ }^{\circ} \mathrm{C}, 1 \mathrm{~h}$ (Table 2). The error limits of the reported values are as follows: $\pm 15 \mathrm{MPa}$ for $\sigma, \pm 9 \mathrm{MPa}$ for $\mathrm{HV}, \pm 1.4 \%$ for $\delta, \pm 0.3 \%$ for $\varepsilon_{r, 1}^{\max }$. 


\section{Summary}

The rotary forging at $350{ }^{\circ} \mathrm{C}$ creates a mixed nanograined/nanosubgrained structure with an average size of structure elements of $118 \pm 7 \mathrm{~nm}$ after forging from the diameter of $20 \mathrm{~mm}$ and $126 \pm 7 \mathrm{~nm}$ after forging from the diameter of $12 \mathrm{~mm}$. The rotary forging at $350{ }^{\circ} \mathrm{C}$ makes it possible to manufacture $3 \mathrm{~m}$-long Ti-Ni rods with much higher mechanical $\left(\sigma_{\mathrm{B}}=1065 \mathrm{MPa}\right.$ after forging from $12 \mathrm{~mm}$ and $1113 \mathrm{MPa}$ after forging from $20 \mathrm{~mm}$ ) and functional (maximum completely recoverable strain of $8.0 \%$, after post deformation annealing at $400{ }^{\circ} \mathrm{C}, 1 \mathrm{~h}$, after both forgings from 12 and $20 \mathrm{~mm}$ ) properties as compared with the initial state before forging (700 MPa and $4.4 \%$, respectively). It is more convenient to start forging from the diameter of $12 \mathrm{~mm}$ because forging from the diameter of $20 \mathrm{~mm}$ is much more difficult, while the difference in the final combination of properties is insignificant.

\section{Acknowledgment}

The present work was carried out with financial support from the Ministry of Science and Education of Russian Federation (State Task No.11.1495.2017/4.6).

\section{References}

[1] T.W. Duerig, K.N. Melton, D. Stöckel, and C.M. Wayman, Eds., Engineering Aspects of Shape Memory Alloys, Butterworth-Heineman, London, 1990.

[2] K. Otsuka, C.M. Wayman, Eds., Shape Memory Materials, Cambridge University Press, Cambridge, 1998.

[3] N. Resnina, V. Rubanik, Eds., Shape Memory Alloys: Properties, Technologies, Opportunities, Trans. Tech. Publications, Praffikon, 2015.

[4] J. M. Jani, M. Leary, A. Subic, and M. A. Gibson, Mater. Des. 56 (2014) 1078-1113.

[5] I.Y. Khmelevskaya, R.D. Karelin, S.D. Prokoshkin, V.A. Andreev, V.S. Yusupov, M.M. Perkas, V.V. Prosvirnin, A.N. Shelest, V.S. Komarov, Phys. Met. Metallogr. 118 (2017) 279-287.

[6] I.Y. Khmelevskaya, R. Kawalla, S.D. Prokoshkin, and V.S. Komarov, IOP Conf. Ser. Mater. Sci. Eng. 63 (2014) 012108.

[7] I. Khmelevskaya, V. Komarov, R. Kawalla, S. Prokoshkin, G. Korpala, J. Mater. Eng. Perform. 26 (2017) 4011.

[8] A. Lotkov, V. Grishkov, O. Kashin, A. Baturin, D. Zhapova, and V. Timkin, Mater. Sci. Found. 81-82 (2015) 245-259.

[9] A.K. Srivastava, D. Schryvers, J. Van Humbeeck, Intermetallics 15 (2007) 1538-1547.

[10] V. Brailovski, S. Prokoshkin, K. Inaekyan, and V. Demers, J. Alloys Compd. 509 (2011) 20662075.

[11]K.A. Polyakova-Vachiyan, E.P. Ryklina, S.D. Prokoshkin, and S.M. Dubinskii, Phys. Met. Metallogr. 117 (2016) 817-827. 